\title{
Brain gadolinium deposition after administration of gadolinium-based contrast agents
}

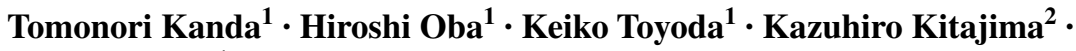 \\ Shigeru Furui ${ }^{1}$
}

Received: 15 September 2015 / Accepted: 9 November 2015 / Published online: 25 November 2015

(C) Japan Radiological Society 2015

\begin{abstract}
Gadolinium-based contrast agents (GBCAs) consist of gadolinium ions and a chelating agent that binds the gadolinium ion tightly so that its toxicity is not manifested. However, in 2013, an association between brain MRI abnormalities and a history of GBCA administration was first reported. Even in patients with normal renal function, increased signal intensity in the dentate nucleus and globus pallidus on unenhanced T1-weighted images showed a positive correlation with previous exposure to linear chelate type GBCAs, but not to macrocyclic chelate type ones. This difference of GBCAs is speculated to reflect the stability of GBCAs, and de-chelated gadolinium deposition has been strongly suspected. Using inductively coupled plasma mass spectroscopy, gadolinium was detected from patients' brains with a history of repeated GBCA administration. In some cases, the gadolinium concentration of a patient's brain with normal renal function exceeded the gadolinium concentration of the skin in nephrogenic systemic fibrosis patients, but without any histological change. The actual risk has not been documented yet, but it seems important to consider the potential unknown risks of residual gadolinium in our decisions regarding GBCA administration, and to make efforts to minimize any residual gadolinium in the patient's body.
\end{abstract}

Tomonori Kanda

k_a@hotmail.co.jp

1 Department of Radiology, Teikyo University School of Medicine, 2-11-1 Kaga, Itabashi-ku, Tokyo 173-8605, Japan

2 Department of Radiology, Kobe University School of Medicine, Kobe, Japan
Keywords Gadolinium · Dentate nucleus · Magnetic resonance $\cdot$ Gadolinium-based contrast agent (GBCA)

\section{Introduction}

Gadolinium is a heavy metal with atomic number 64 that belongs to the lanthanide family. Like other lanthanide metals, the most common oxidation state of gadolinium is +3 and the ionic radius is $0.99 \AA$. The ionic radius of gadolinium is almost equal to that of $\mathrm{Ca}^{2+}$, and $\mathrm{Gd}^{3+}$ can compete with $\mathrm{Ca}^{2+}$ and become toxic in biological systems. To reduce the toxicity of $\mathrm{Gd}^{3+}$, it has to be administered to humans in chelated forms to avoid the presence of free gadolinium [1, 2]. A gadolinium-based contrast agent (GBCA) was first introduced by Runge at the Radiologic Society of North America meeting in Chicago in 1982 $[3,4]$. GBCAs were soon produced commercially, gadopentetate dimeglumine (Gd-DTPA, Magnevist) being the first approved for clinical use in 1988, followed by gadoterate meglumine (Gd-DOTA, Dotarem), gadoteridol (Gd-HP-DO3A, ProHance), and gadodiamide (Gd-DTPABMA, Ominiscan) [5]. GBCAs have been used internationally for more than a quarter century in more than 100 million patients.

\section{Concept of the gadolinium-based contrast agents}

GBCAs were anticipated to have high contrast efficiency, safety due to their high stability and rapid excretion, low viscosity, and low osmolality. To obtain a high contrast image with a low dose of GBCA, high contrast efficiency of GBCA is needed. The contrast efficiency was evaluated with the ability to reduce $T 1$ and/or $T 2$ 
in tissue. Each agent's fundamental ability to reduce $T 1$ and $T 2$ is referred to as its "relaxivity" $R 1(=1 / T 1)$ and $R 2(=1 / T 2)$. High $R 1$ agents induce a shorter $T 1$ and higher contrast efficiency. Because the gadolinium ion is toxic, GBCAs consist of gadolinium ions and a chelating agent that binds the gadolinium ion tightly so that its toxicity is not manifested. To maintain the GBCA's low toxicity, the dissociation of gadolinium ion should be minimal in vivo and gadolinium should be rapidly excreted from the body [2, 3, 5]. The stability of GBCA has been evaluated with kinetic stability and thermodynamic stability in the laboratory. The thermodynamic stability is the ratio of free gadolinium ions in equilibrium, and is evaluated with the thermodynamic stability constant $\left(K_{\text {therm }}\right)$ and conditional stability constant $\left(K_{\text {cond }}\right)$. These factors reflect the affinity of gadolinium ion for its ligand at high basic $\mathrm{pH}$ and 7.4 in equilibrium in a water solution. The kinetic stability reflects the rate of gadolinium dissociation, in other words, how fast the gadolinium ion is released from GBCAs. Kinetic stability is evaluated with the dissociation half-life time $\left(T_{1 / 2}\right)$ of GBCA in various conditions. Both thermodynamic stability and kinetic stability reflect the stability of GBCA to some extent, but the stability in vivo cannot be evaluated exactly with these parameters [5-7]. To perform rapid infusion without inducing an acute reaction, low viscosity and osmolality are needed.

Various types of GBCA have been developed to satisfy these conditions. GBCAs are divided into linear and macrocyclic, and subdivided into ionic and non-ionic types according to their chelate structure. Generally, macrocyclic GBCAs are more stable than linear GBCAs. The ionic GBCAs are generally slightly more stable than nonionic GBCAs, but have higher osmolality. A large amount of excess chelate was added to unstable GBCAs to minimize the release of free gadolinium. The characteristics of GBCAs are summarized in Table $1[2,3,5]$.

\section{Gadolinium deposition in patients with normal renal function}

Since the first reports on GBCAs, there has been concern about gadolinium deposition in tissue. Tweedle and colleagues [8-11] evaluated gadolinium retention in rats and mice after injection of ${ }^{153} \mathrm{Gd}$-labeled GBCAs and free gadolinium, such as $\mathrm{GdCl}_{3}$ gadolinium acetate. When "free gadolinium" is administered, most of the gadolinium deposits in the liver and bone. Very little is excreted and clearance has been reported to be approximately 1-3\% per day. When different chelate types of GBCA are administered, the distribution of gadolinium is very similar during the first $24 \mathrm{~h}$. At 7 and 14 days, the remaining gadolinium is found mainly in kidney, liver, and bone. The amount of remaining gadolinium differs among the chelate types of GBCA [gadodiamide (linear non-ionic GBCA) > gadopentetate dimeglumine (linear ionic GBCA) $\approx$ gadoterate meglumine (macrocyclic ionic GBCA) $\approx$ gadoteridol (macrocyclic ionic GBCA)] [11]. Sieber [12] also evaluated the gadolinium retention in rats by inductive coupled plasma atomic emission spectroscopy (ICP-AES) and found that the gadolinium deposition differed among the chelate types of GBCA [gadodiamide (linear non-ionic GBCA) > gadoversetamide (linear non-ionic GBCA) > gadopentetate dimeglumine (linear ionic GBCA) > gadobenate dimeglumine (linear ionic GBCA) $\approx$ gadobutrol (macrocyclic nonionic GBCA) $\approx$ gadoterate meglumine (macrocyclic ionic GBCA)]. This difference was attributed to greater gadolinium release from the chelate.

Studies on gadolinium deposition in humans with normal renal function are limited. Gibby [13], White [14], and Darrah [15] analyzed the gadolinium deposition in femoral bone specimens from total hip arthroplasties, and Xia [16] analyzed it in brain tumor tissue. Their data suggested that gadolinium is deposited even in persons without renal dysfunction. Moreover, Gibby and White [13, 14] found 4-fold higher levels of gadolinium in the bone of subjects who received gadodiamide (linear non-ionic GBCA) than for those who received gadoteridol (macrocyclic non-ionic GBCA) by using inductively coupled plasma mass spectroscopy (ICP-MS). Frenzel [17] evaluated the dissociation of 9 types of GBCA in human serum at $37^{\circ} \mathrm{C}$. This was an in vitro study, but the release of gadolinium from linear GBCA was confirmed. The initial gadolinium dissociation rate of linear GBCAs was 0.07-0.44\%, and that of macrocyclic GBCAs was less than $0.007 \%$. After a 15-day incubation period, the released rate of gadolinium linear nonionic GBCAs was 20-21\%, in contrast to 1.1-1.9\% for linear ionic GBCAs, and under $0.1 \%$ for macrocyclic GBCAs.

\section{Nephrogenic systemic fibrosis (NSF)}

GBCAs are considered very safe in general with severe adverse effects only rarely observed. However, in 1997, Cowper [18] reported "scleromyxoedema-like cutaneous diseases in renal-dialysis patients". In 2006, Grobner [19] and Marckmann [20] suggested a link between these skin lesions and a history of exposure to GBCAs, and this condition was named nephrogenic systemic fibrosis (NSF) [2]. The common presentation of NSF is acute to subacute onset of limb swelling, redness and pain, particularly in the lower limbs, leading in severe cases to joint contractures and immobility. Additionally, NSF may contribute to death through scarring of the body organs. Gadolinium 
Table 1 The characteristics of gadolinium-based contrast agents [2, 3, 5]

\begin{tabular}{|c|c|c|c|c|c|c|c|c|c|}
\hline Acronym & Gd-DTPA & Gd-DOTA & $\begin{array}{l}\text { Gd-HP- } \\
\text { DO3A }\end{array}$ & $\begin{array}{l}\text { Gd-DTPA- } \\
\text { BMA }\end{array}$ & $\begin{array}{l}\text { Gd-DO3A- } \\
\text { butrol }\end{array}$ & $\begin{array}{l}\text { Gd-DTPA- } \\
\text { BMEA }\end{array}$ & Gd-BOPTA & $\begin{array}{l}\text { Gd-EOB- } \\
\text { DTPA }\end{array}$ & MS-325 \\
\hline Trade name & Magnevist & Dotarem & ProHance & Omniscan & Gadovist & OptiMARK & MultiHance & $\begin{array}{l}\text { Primovist } \\
\text { Eovist }\end{array}$ & $\begin{array}{l}\text { Vasovist } \\
\text { Ablavarr }\end{array}$ \\
\hline $\begin{array}{c}\text { Generic } \\
\text { name }\end{array}$ & $\begin{array}{l}\text { Gado- } \\
\text { pentetate } \\
\text { dimeglu- } \\
\text { mine }\end{array}$ & $\begin{array}{l}\text { Gadoterate } \\
\text { meglu- } \\
\text { mine }\end{array}$ & Gadoteridol & Gadodiamide & Gadobutrol & $\begin{array}{l}\text { Gadoverse- } \\
\text { tamide }\end{array}$ & $\begin{array}{l}\text { Gadobenate } \\
\text { dimeglu- } \\
\text { mine }\end{array}$ & $\begin{array}{l}\text { Gadoxetic } \\
\text { acid diso- } \\
\text { dium }\end{array}$ & $\begin{array}{l}\text { Gadofos- } \\
\text { veset } \\
\text { trisodium }\end{array}$ \\
\hline Company & Bayer & Guerbet & Bracco & $\begin{array}{l}\text { GE-health- } \\
\text { care }\end{array}$ & Bayer & Covidien & Bracco & Bayer & Lantheus \\
\hline $\begin{array}{l}\text { First } \\
\text { approval }\end{array}$ & 1986, EU & 1989, EU & 1992, USA & 1993, USA & 1998, EU & 1999, USA & 1997, EU & 2004, EU & 2005, EU \\
\hline $\begin{array}{l}\text { Doses in } \\
\text { Japan } \\
(\mathrm{mmol} / \mathrm{kg})\end{array}$ & $0.1-0.2$ & 0.1 & $0.1-0.2$ & 0.1 & 0.1 & $--^{a, b}$ & $--^{a, b}$ & 0.025 & $--^{\mathrm{a}, \mathrm{b}}$ \\
\hline $\begin{array}{l}\text { Excess } \\
\text { chelate }\end{array}$ & $0.1 \%$ & $0 \%$ & $0.1 \%$ & $5 \%$ & $0.1 \%$ & 28.4 & $0 \%$ & $0.5 \%$ & $0.1 \%$ \\
\hline Structure & Linear & $\begin{array}{l}\text { Macrocy- } \\
\text { clic }\end{array}$ & $\begin{array}{l}\text { Macrocy- } \\
\text { clic }\end{array}$ & Linear & $\begin{array}{l}\text { Macrocy- } \\
\text { clic }\end{array}$ & Linear & Linear & Linear & Linear \\
\hline Ionicity & Ionic & Ionic & Nonionic & Nonionic & Nonionic & Nonionic & Ionic & Ionic & Ionic \\
\hline Stability & Intermediate & High & High & Low & High & Low & Intermediate & $\begin{array}{l}\text { Intermedi- } \\
\text { ate }\end{array}$ & $\begin{array}{l}\text { Intermedi- } \\
\text { ate }\end{array}$ \\
\hline NSF risk & High & Low & Low & High & Low & High & Intermediate & $\begin{array}{l}\text { Intermedi- } \\
\text { ate }\end{array}$ & $\begin{array}{l}\text { Intermedi- } \\
\text { ate }\end{array}$ \\
\hline Osmolality & 1960 & 1350 & 630 & 789 & 1603 & 110 & 1970 & 688 & 825 \\
\hline Viscosity & 2.9 & 2.0 & 1.3 & 1.4 & 5.0 & 2.0 & 5.3 & 12 & 2.1 \\
\hline $\log K_{\text {therm }}$ & 22.1 & 25.6 & 23.8 & 16.9 & 21.8 & 16.6 & 22.6 & 23.5 & 22.1 \\
\hline $\log K_{\text {cond }}$ & 17.7 & 19.3 & 17.1 & 14.9 & 14.7 & 15.0 & 18.4 & 18.7 & 18.9 \\
\hline$T_{1 / 2}$ & $<5 \mathrm{~s}$ & $338 \mathrm{~h}$ & $3.9 \mathrm{~h}$ & $<5 \mathrm{~s}$ & $43 \mathrm{~h}$ & $<5 \mathrm{~s}$ & $<5 \mathrm{~s}$ & $<5 \mathrm{~s}$ & $<5 \mathrm{~s}$ \\
\hline $\begin{array}{l}\text { Relaxivity }{ }^{\mathrm{a}, \mathrm{b}} \\
(R 1 / R 2,1.5 \mathrm{~T})\end{array}$ & $\begin{array}{r}3.9-4.1 / \\
4.6-5.3\end{array}$ & $3.6 / 4.3$ & $4.1 / 5.0$ & $4.3 / 5.2$ & $\begin{array}{r}4.7-5.2 / \\
6.1-7.5\end{array}$ & $4.7 / 5.2$ & $\begin{array}{l}6.3-7.9 / \\
8.7-18.9\end{array}$ & $6.9 / 8.7$ & $19.0 / 34.0$ \\
\hline $\begin{array}{l}\text { Relaxivity }{ }^{\mathrm{a}, \mathrm{b}} \\
(R 1 / R 2,3 \mathrm{~T})\end{array}$ & $3.7-3.9 / 5.2$ & $3.5 / 4.9$ & $3.7 / 5.7$ & $4.0 / 5.6$ & $\begin{array}{l}4.5-5.0 / \\
6.3-7.1\end{array}$ & $4.5 / 5.9$ & $\begin{array}{l}5.5-5.9 / \\
11.0-17.5\end{array}$ & $6.2 / 11.0$ & $9.9 / 60.0$ \\
\hline Clearance & Renal & Renal & Renal & Renal & Renal & Renal & $\begin{array}{l}96 \% \text { renal } \\
4 \% \text { hepatic }\end{array}$ & $\begin{array}{l}50 \% \text { renal } \\
50 \% \\
\text { hepatic }\end{array}$ & $\begin{array}{l}79 \%-94 \% \\
\text { renal } \\
5 \% \text { hepatic }\end{array}$ \\
\hline
\end{tabular}

$\overline{K_{\text {therm }}}$ thermodynamic stability constant, $K_{\text {cond }}$ conditional stability constant, $T_{1 / 2}$ dissociation half-time at pH 1.0 and $25{ }^{\circ} \mathrm{C}, E U$ Europe, $U S A$ United States of America

${ }^{\text {a }}$ Not commercially available in Japan

b Values in $1 \mathrm{mmol}^{-1} \mathrm{~s}^{-1}$ (plasma, $37^{\circ} \mathrm{C}$ )

can be detected from the skin tissue of NSF [21-23]. Because the development of NSF symptoms takes several years, the true incidence of NSF has been difficult to determine. According to the database of unconfounded NSF cases [24], the incidence of NSF differs according to the chelate structure of various GBCAs. Approximately $75 \%$ of NSF was associated with gadodiamide (linear non-ionic GBCA), around $23 \%$ with gadopentate dimeglumine (linear ionic GBCA) and only a few cases with other GBCAs. Most cases of NSF were associated with linear chelate GBCAs, with instability of the chelate compound implicated as the factor inducing NSF [25-30]. The European Society of Urogenital Radiology (ESUR) [29] and European Medicines Agency (EMA) [24] classified the NSF risk of GBCAs into three groups (high risk, intermediate risk, low risk), and recommended that high risk GBCAs not be administered to patients on hemodialysis, with eGFR (estimated glomerular filtration rate) under 30, or acute renal dysfunction. The American College of Radiology (ACR) [30] identified the GBCAs associated with the greatest apparent NSF-associated risk (gadodiamide, gadopentetate dimeglumine and gadoversetamide), and recommended that their administration be avoided in such patients. Until now, no definitive treatment for NSF has been devised and radiologists play an essential role in preventing its occurrence [24-30]. 


\section{Evaluation of gadolinium deposition with brain MRI}

In 2013, the association of brain MRI abnormality and a history of GBCA administration was first reported by Kanda et al. [31, 32]. Increased signal intensity in the dentate nucleus and globus pallidus on unenhanced T1-weighted images (T1WI) showed a positive correlation with previous exposure to linear chelate type GBCAs (gadopentetate dimeglumine or gadodiamide) even in patients with normal renal function. Their observation revealed an apparent dose-response relationship wherein the greater the number of previous GBCA administrations the greater was the degree of observed intracranial $\mathrm{T} 1$ hyper-intensity. The hyper-intensity appeared with more than 5 past administrations of GBCA. Previously, hyperintensity in the dentate nucleus on T1WI had been attributed to a secondary progressive subtype of multiple sclerosis [33] or irradiation [34]. However, Kanda et al.'s report showed that the cause of hyper-intense dentate nucleus on T1WI was not irradiation, but multiple GBCA administrations. Shortly thereafter, Errate et al. [35-37] also reported the presence of hyper-intensity in the dentate nucleus in parallel with the frequency of past gadodiamide administration. The same phenomenon was also reported in children by Roberts et al. [38]. The next step was the need to clarify the relationship between the signal intensity change and chelate type of GBCAs. In 2014, Kanda et al. [39] reported that hyper-intensity in the dentate nucleus was associated with previous repeated administration of gadopentetate dimeglumine (linear GBCA), but not gadoteridol (macrocyclic GBCA). Radbruch [40] also reported that repeated administration of gadopentetate dimeglumine (linear GBCA) caused hyper-intensity of the dentate nucleus whereas gadoterate meglumine (macrocyclic GBCA) did not.

In these results, dentate nucleus hyper-intensity was caused by high NSF risk GBCAs, and not by low NSF risk ones. Gadobenate dimeglumine is a linear nonionic GBCA, which seldom causes NSF [41], and is classified as an intermediate NSF risk GBCA. Ramalho et al. [42] compared gadodiamide (linear non-ionic GBCA, high NSF risk) and gadobenate dimeglumine (linear ionic GBCA, intermediate NSF risk) using the MRI signal intensity change of the dentate nucleus, and noted such a change only with gadodiamide. Weberling et al. [43] reported that MRI signal intensity change of the dentate nucleus occurred even in subjects with multiple administration of gadobenate dimeglumine (linear ionic GBCA, intermediate NSF risk), but the signal change was gadopentetate dimeglumine (linear ionic GBCA, high NSF risk) > gadobenate dimeglumine (linear ionic GBCA, intermediate NSF risk) > gadoterate meglumine (macrocyclic GBCA, low NSF risk). The intermediate NSF risk GBCAs may be less likely to cause intracranial gadolinium deposition, though other intermediate NSF risk GBCAs need to be evaluated to confirm this.

An exception has also been reported by Stojanov et al. [44]. They evaluated the relationship between the number of past gadobutrol (non-ionic macrocyclic GBCA, low NSF risk) administrations and signal change of the dentate nucleus, with the signal change detectable in the dentate nucleus with ROI analysis. However, no hyper-intensity in the dentate nucleus on T1WI could be visually noted in their presented figure, despite being seen in all other previous reports [32, 35-40, 42, 43]. In addition, they did not rule out the effect of confounding factors, or include control subjects [45]. Radbruch [46] also evaluated the relationship between the number of past gadobutrol administrations and signal change of the dentate nucleus and globus pallidus, but there were no signal increases, even though the total dose applied here was considerably larger than Stojanov et al. reported [44]. The macrocyclic GBCA may also cause hyper-intensity in the dentate nucleus, but this must be confirmed by further investigations.

\section{Evaluation of gadolinium deposition by histological analysis}

Hyper-intensity on T1WI is caused not only by gadolinium, but also by calcium, manganese, iron, lipid, and other substances [47]. To determine the cause of signal change on T1WI, the detection of gadolinium by histological analysis was needed. McDonald et al. [48] and Kanda et al. [49] confirmed the considerably higher gadolinium deposition in these hyper-intensity regions as compared to other brain regions using ICP-MS. In addition, McDonald [48] confirmed that gadolinium accumulated mainly within the endothelial wall, but also in the neural tissue, passing through the blood brain barrier (BBB). Despite direct evidence of gadolinium deposition within neuronal tissues, no histologic change of neural tissues was detected.

Robert and colleagues [50] injected $0.6 \mathrm{mmol}$ of gadolinium per kilogram per injection (4 injections per week for 5 weeks) of gadodiamide (linear GBCA), gadoterate meglumine (macrocyclic GBCA), or hyperosmolar saline into rats, and evaluated the gadolinium deposition. Signal change of the dentate nucleus on T1WI was observed only in the gadodiamide-exposed rats, and the total gadolinium concentration of gadodiamide-exposed rat brain was 14-fold higher than in the gadoterate meglumine exposed rats as determined by ICP-MS. Since the effect of repeated GBCA administration had not been evaluated before, Runge [51] recommended that all of the currently approved 
GBCAs be evaluated by the same methods as Robert's to better determine their safety.

On the other hand, these studies focused only on the relationship between the dose of gadolinium and residual gadolinium, and further study was needed to verify that the residual gadolinium was actually responsible for the signal change.

\section{Mechanism of gadolinium deposition}

The mechanism of gadolinium deposition in the brain has not yet been well clarified. Since the degree of brain gadolinium deposition was shown to vary according to its chelate structure, the degree of de-chelation probably plays a role. Frenzel et al. [52] evaluated the de-chelation rate of GBCA after a 15-day incubation period at $37{ }^{\circ} \mathrm{C}$ in human serum in vitro. The de-chelation rates were nonionic linear GBCAs (20-21\%) > ionic linear GBCAs (1.1$1.9 \%) \gg$ macrocyclic GBCAs $(<0.1 \%)$.

In vivo, the presence of other metal ions that compete with gadolinium for chelation could result in transmetallation, that is, de-chelation of gadolinium assisted by another endogenous metal ion. Endogenous ions present in the body that induce transmetallation include $\mathrm{Na}^{+}, \mathrm{K}^{+}, \mathrm{Mg}^{2+}$, $\mathrm{Ca}^{2+}, \mathrm{Fe}^{3+}$, and $\mathrm{Zn}^{2+}$. Free $\mathrm{Fe}^{3+}$ and $\mathrm{Cu}^{2+}$ are present in very small amounts in the blood and $\mathrm{Na}^{+}, \mathrm{K}^{+}, \mathrm{Mg}^{2+}$, and $\mathrm{Cu}^{2+}$ have a weak ability to chelate GBCAs. Therefore, $\mathrm{Zn}^{2+}$ was surmised to play an important role in transmetallation [1, 5]. Puttagunta et al. [53] and subsequently Kimura et al. [54] showed that $\mathrm{Zn}^{2+}$ levels were elevated in the urine of subjects administered linear GBCAs (gadopentetate dimeglumine and gadodiamide), but not in those administered macrocyclic GBCAs (gadoterate meglumine or gadoteridol). It was unclear whether the $\mathrm{Zn}^{2+}$ excretion was due to the transmetallation or excess chelation of GBCAs, but this study indicated that $\mathrm{Zn}^{2+}$ promoted in some way the chelation of GBCAs.

The results of MRI and autopsy analysis demonstrated that gadolinium can pass through the BBB and accumulate in the brain with a concentration gradient. High concentration areas of gadolinium were the dentate nucleus, inner segment of the globus pallidus, and pulvinar of the thalamus [48, 49], with iron or calcium also showing relatively higher concentrations in these regions [55, 56]. Gadolinium is probably not transported passively, but rather by some biological mechanism(s) such as metal transporter(s) $[57,58]$.

\section{Safety and GBCAs}

With repeated GBCA administration, gadolinium accumulates in the brain and in bone even with normal renal function. However, the risk of gadolinium deposition is unproven. NSF is fatal and no consistently successful treatment is available, but NSF develops only in patients with severe renal dysfunction. McDonald et al. [48] analyzed the dentate nucleus of 13 patients without severe renal dysfunction, and found a gadolinium concentration of 0.1-58.8 $\mu \mathrm{g} / \mathrm{g}$. Christensen et al. [23] analyzed $13 \mathrm{NSF}$ patients' skin and found a gadolinium concentration of $6.3-348.7 \mu \mathrm{g} / \mathrm{g}$. Some of the gadolinium concentrations in the dentate nucleus were higher than those in NSF patients' skin. In 2015, Gathings et al. [59] reported two cases of gadolinium-associated skin plaques in patients without severe renal dysfunction. This plaque was reported as the sclerotic body that had been linked to NSF [60-62]. The gadolinium-associated plaques caused only mild symptoms, and were associated with few problems clinically.

GBCA has been used for over 30 years, and gadolinium deposition causes no severe problems except for NSF. Even though the potential risk of gadolinium deposition should not be ignored, GBCA administration should not be restricted when truly indicated. And efforts should be made to minimize any residual gadolinium in the patient's body [63]. The American Food and Drug Administration (FDA) began to evaluate the risk of gadolinium deposition in July 2015 [64], and it is anticipated that the magnitude of the potential risk of gadolinium deposition will become gradually apparent. EMA [24], ACR [30], ESUR [29] and the Japan Radiological Society [65] have not proposed any new guidelines concerning gadolinium deposition yet. Radiologists should continue to keep in mind the risks of residual gadolinium.

\section{Conclusion}

Knowledge regarding gadolinium deposition in patients with normal renal function has dramatically increased since 2013. Gadolinium is now known to gradually accumulate in brain and bone, even in patients with normal renal function. The amount of residual gadolinium differs markedly among the chelate type of GBCAs, but there have been no reports of severe complications due to gadolinium deposition except for NSF. The actual risk has not been proven yet, but the potential unknown risks of residual gadolinium should be considered in our decisions regarding GBCA administration, and continuous efforts should be made to minimize the frequency of GBCA administration whenever possible.

\section{Compliance with ethical standards}

Conflict of interest The authors declare that they have no conflict of interest. 


\section{References}

1. Sherry AD, Caravan P, Lenkinski RE. A primer on gadolinium chemistry. J Magn Reson Imaging. 2009;30:1240-8.

2. Thomsen HS, Morcos SK, Almén T, Bellin MF, Bertolotto M, Bongartz $\mathrm{G}$, et al. Nephrogenic systemic fibrosis and gadolinium-based contrast media: updated ESUR Contrast Medium Safety Committee guidelines. Eur Radiol. 2013;23:307-18.

3. Runge VM, Ai T, Hao D, Hu X. The developmental history of the gadolinium chelates as intravenous contrast media for magnetic resonance. Invest Radiol. 2011;46:807-16.

4. Runge VM, Stewart RG, Clanton JA, Jones MM, Lukehart $\mathrm{CM}$, Partain CL, et al. Work in progress: potential oral and intravenous paramagnetic NMR contrast agents. Radiology. 1983;147:789-91.

5. Hao D, Ai T, Goerner F, Hu X, Runge VM, Tweedle M. MRI contrast agents: basic chemistry and safety. J Magn Reson Imaging. 2012;36:1060-71.

6. Port M, Idée JM, Medina C, et al. Efficiency, thermodynamic and kinetic stability of marketed gadolinium chelates and their possible clinical consequences: a critical review. Biometals. 2008;21:469-90.

7. Idée JM, Port M, Robic C, et al. Role of thermodynamic and kinetic parameters in gadolinium chelate stability. J Magn Reson Imaging. 2009;30:1249-58.

8. Wedeking P, Tweedle M. Comparison of the biodistribution of 153Gd-labeled Gd(DTPA)2-, Gd(DOTA)-, and Gd(acetate)n in mice. Int J Radiat Appl Instrum B. 1988;15:395-402.

9. Wedeking P, Kumar K, Tweedle MF. Dissociation of gadolinium chelates in mice: relationship to chemical characteristics. Magn Reson Imaging. 1992;10:641-8.

10. Wedeking P, Kumar K, Tweedle MF. Dose-dependent biodistribution of $[153 \mathrm{Gd}] \mathrm{Gd}($ acetate $) \mathrm{n}$ in mice. Nucl Med Biol. 1993;20:679-91.

11. Tweedle MF, Wedeking P, Kumar K. Biodistribution of radiolabeled, formulated gadopentetate, gadoteridol, gadoterate, and gadodiamide in mice and rats. Invest Radiol. 1995;30:372-80.

12. Sieber MA, Lengsfeld P, Frenzel T, Golfier S, Schmitt-Willich $\mathrm{H}$, Siegmund F, et al. Preclinical investigation to compare different gadolinium-based contrast agents regarding their propensity to release gadolinium in vivo and to trigger nephrogenic systemic fibrosis-like lesions. Eur Radiol. 2008;18:2164-73.

13. Gibby WA, Gibby KA, Gibby WA. Comparison of Gd DTPABMA (Omniscan) versus Gd HP-DO3A (ProHance) retention in human bone tissue by inductively coupled plasma atomic emission spectroscopy. Invest Radiol. 2004;39:138-42.

14. White GW, Gibby WA, Tweedle MF. Comparison of Gd(DTPABMA) (Omniscan) versus Gd(HP-DO3A) (ProHance) relative to gadolinium retention in human bone tissue by inductively coupled plasma mass spectroscopy. Invest Radiol. 2006;41:272-8.

15. Darrah TH, Prutsman-Pfeiffer JJ, Poreda RJ, Ellen Campbell M, Hauschka PV, Hannigan RE. Incorporation of excess gadolinium into human bone from medical contrast agents. Metallomics. 2009;1:479-88.

16. Xia D, Davis RL, Crawford JA, Abraham JL. Gadolinium released from MR contrast agents is deposited in brain tumors: in situ demonstration using scanning electron microscopy with energy dispersive X-ray spectroscopy. Acta Radiol. 2010;51:1126-36.

17. Frenzel T, Lengsfeld P, Schirmer H, Hütter J, Weinmann HJ. Stability of gadolinium-based magnetic resonance imaging contrast agents in human serum at $37^{\circ} \mathrm{C}$. Invest Radiol. 2008;43:817-28.

18. Cowper SE, Robin HS, Steinberg SM, Su LD, Gupta S, LeBoit PE. Scleromyxoedema-like cutaneous diseases in renal-dialysis patients. Lancet. 2000;356:1000-1.
19. Grobner T. Gadolinium - a specific trigger for the development of nephrogenic fibrosing dermopathy and nephrogenic systemic fibrosis? Nephrol Dial Transplant. 2006;21:1104-8.

20. Marckmann P, Skov L, Rossen K, Dupont A, Damholt MB, Heaf JG, et al. Nephrogenic systemic fibrosis: suspected causative role of gadodiamide used for contrast-enhanced magnetic resonance imaging. J Am Soc Nephrol. 2006;17:2359-62.

21. Boyd AS, Zic JA, Abraham JL. Gadolinium deposition in nephrogenic fibrosing dermopathy. J Am Acad Dermatol. 2007;56:27-30.

22. High WA, Ayers RA, Chandler J, Zito G, Cowper SE. Gadolinium is detectable within the tissue of patients with nephrogenic systemic fibrosis. Am Acad Dermatol. 2007;56:21-6.

23. Christensen KN, Lee CU, Hanley MM, Leung N, Moyer TP, Pittelkow MR. Quantification of gadolinium in fresh skin and serum samples from patients with nephrogenic systemic fibrosis. J Am Acad Dermatol. 2011;64:91-6.

24. European Medicines Agency. Assessment report for gadoliniumcontaining contrast agents. http://www.ema.europa.eu/docs/ en_GB/document_library/Referrals_document/gadolinium_31/ WC500099538.pdf. Published 1 July 2010. Accessed 5 October 2015.

25. Khawaja AZ, Cassidy DB, Shakarchi J, McGrogan DG, Inston NG, Jones RG. Revisiting the risks of MRI with Gadolinium based contrast agents-review of literature and guidelines. Insights Imaging. 2015;6:553-8.

26. Sadowski EA, Bennett LK, Chan MR, Wentland AL, Garrett AL, Garrett RW, et al. Nephrogenic systemic fibrosis: risk factors and incidence estimation. Radiology. 2007;243:148-57.

27. Kaewlai R, Abujudeh H. Nephrogenic systemic fibrosis. AJR Am J Roentgenol. 2012;199:W17-23.

28. Heverhagen JT, Krombach GA, Gizewski E. Application of extracellular gadolinium-based MRI contrast agents and the risk of nephrogenic systemic fibrosis. RöFo Fortschr Roentgenstr. 2014;186:661-9.

29. European Society of Urogenital Radiology (ESUR). ESUR guidelines on contrast media version 9.0. Vienna: ESUR Head Office; 2014. p. 16-8.

30. ACR manual on contrast media, v10.1. http://www.acr.org/ / media/ACR/Documents/PDF/QualitySafety/Resources/Contrast\%20Manual/2015_Contrast_Media.pdf. Published 28 August 2015. Accessed 5 October 2015.

31. Kanda T, Kawaguchi H. Hyperintense dentate nucleus and globus pallidus on unenhanced T1-weighted MR images are associated with gadolinium-based contrast media. Neuroradiol. 2013;55:1268-9.

32. Kanda T, Ishii K, Kawaguchi H, Kitajima K, Takenaka D. High signal intensity in the dentate nucleus and globus pallidus on unenhanced T1-weighted MR images: relationship with increasing cumulative dose of a gadolinium-based contrast material. Radiology. 2014;270:834-41.

33. Roccatagliata L, Vuolo L, Bonzano L, Pichiecchio A, Mancardi GL. Multiple sclerosis: hyperintense dentate nucleus on unenhanced T1-weighted MR images is associated with the secondary progressive subtype. Radiology. 2009;251:503-10.

34. Kasahara S, Miki Y, Kanagaki M, Yamamoto A, Mori N, Sawada T, et al. Hyperintense dentate nucleus on unenhanced T1-weighted MR images is associated with a history of brain irradiation. Radiology. 2011;258:222-8.

35. Errante Y, Cirimele V, Mallio CA, Di Lazzaro V, Zobel BB, Quattrocchi CC. Progressive increase of T1 signal intensity of the dentate nucleus on unenhanced magnetic resonance images is associated with cumulative doses of intravenously administered gadodiamide in patients with normal renal function, suggesting dechelation. Invest Radiol. 2014;49:685-90.

36. Quattrocchi CC, Mallio CA, Errante Y, Cirimele V, Carideo L, Ax A, et al. Gadodiamide and dentate nucleus $\mathrm{T} 1$ hyperintensity 
in patients with meningioma evaluated by multiple follow-up contrast-enhanced magnetic resonance examinations with no systemic interval therapy. Invest Radiol. 2015;50:470-2.

37. Adin ME, Kleinberg L, Vaidya D, Zan E, Mirbagheri S, Yousem DM. Hyperintense dentate nuclei on T1-weighted MRI: relation to repeat gadolinium administration. AJNR Am J Neuroradiol. 2015;36(10):1859-65. doi:10.3174/ajnr.A4378.

38. Roberts DR, Holden KR. Progressive increase of T1 signal intensity in the dentate nucleus and globus pallidus on unenhanced T1-weighted MR images in the pediatric brain exposed to multiple doses of gadolinium contrast. Brain Dev. 2015. doi:10.1016/j.braindev.2015.08.009.

39. Kanda T, Osawa M, Oba H, Toyoda K, Kotoku J, Haruyama $\mathrm{T}$, et al. High signal intensity in dentate nucleus on unenhanced T1-weighted MR images: association with linear versus macrocyclic gadolinium chelate administration. Radiology. 2015;275:803-9.

40. Radbruch A, Weberling LD, Kieslich PJ, Eidel O, Burth S, Kickingereder $\mathrm{P}$, et al. Gadolinium retention in the dentate nucleus and globus pallidus is dependent on the class of contrast agent. Radiology. 2015;275:783-91.

41. Nandwana SB, Moreno CC, Osipow MT, Sekhar A, Cox KL. Gadobenate dimeglumine administration and nephrogenic systemic fibrosis: is there a real risk in patients with impaired renal function? Radiology. 2015;276:741-7.

42. Ramalho J, Castillo M, AlObaidy M, Nunes RH, Ramalho M, Dale BM, et al. High signal intensity in globus pallidus and dentate nucleus on unenhanced T1-weighted MR images: evaluation of two linear gadolinium-based contrast agents. Radiology. 2015;276:836-44.

43. Weberling LD, Kieslich PJ, Kickingereder P, et al. Increased signal intensity in the dentate nucleus on unenhanced T1-weighted images after gadobenate dimeglumine administration. Invest Radiol. 2015;50(11):743-8. doi:10.1097/ RLI.0000000000000206.

44. Stojanov DA, Aracki-Trenkic A, Vojinovic S, Benedeto-Stojanov $\mathrm{D}$, Ljubisavljevic $\mathrm{S}$, et al. Increasing signal intensity within the dentate nucleus and globus pallidus on unenhanced T1W magnetic resonance images in patients with relapsing-remitting multiple sclerosis: correlation with cumulative dose of a macrocyclic gadolinium-based contrast agent, gadobutrol. Eur Radiol. 2015. doi:10.1007/s00330-015-3879-9.

45. Agris J, Pietsch H, Balzer T. What evidence is there that gadobutrol causes increasing signal intensity within the dentate nucleus and globus pallidus on unenhanced T1W MRI in patients with RRMS? Eur Radiol. 2015. doi:10.1007/s00330-015-4019-2.

46. Radbruch A, Weberling LD, Kieslich PJ, et al. High-signal intensity in the dentate nucleus and globus pallidus on unenhanced T1-weighted images: evaluation of the macrocyclic gadolinium-based contrast agent gadobutrol. Invest Radiol. 2015;50(12):805-10. doi:10.1097/RLI.0000000000000227..

47. Ginat DT, Meyers SP. Intracranial lesions with high signal intensity on T1-weighted MR images: differential diagnosis. Radiographics. 2012;32:499-516.

48. McDonald RJ, McDonald JS, Kallmes DF, Jentoft ME, Murray DL, Thielen KR, et al. Intracranial gadolinium deposition after contrast-enhanced MR imaging. Radiology. 2015;275:772-82.

49. Kanda T, Fukusato T, Matsuda M, Toyoda K, Oba H, Kotoku J, et al. Gadolinium-based contrast agent accumulates in the brain even in subjects without severe renal dysfunction: evaluation of autopsy brain specimens with inductively coupled plasma mass spectroscopy. Radiology. 2015;276:228-32.
50. Robert P, Lehericy S, Grand S, Violas X, Fretellier N, Idée JM, et al. T1-weighted hypersignal in the deep cerebellar nuclei after repeated administrations of gadolinium-based contrast agents in healthy rats: difference between linear and macrocyclic agents. Invest Radiol. 2015;50:473-80.

51. Runge VM. Commentary on T1-weighted hypersignal in the deep cerebellar nuclei after repeated administrations of gadolinium-based contrast agents in healthy rats: difference between linear and macrocyclic agents. Invest Radiol. 2015;50:481-2.

52. Frenzel T, Lengsfeld P, Schirmer H, Hütter J, Weinmann HJ. Stability of gadolinium-based magnetic resonance imaging contrast agents in human serum at $37^{\circ} \mathrm{C}$. Invest Radiol. 2008;43:817-28.

53. Puttagunta NR, Gibby WA, Smith GT. Human in vivo comparative study of zinc and copper transmetallation after administration of magnetic resonance imaging contrast agents. Invest Radiol. 1996;31:739-42.

54. Kimura J, Ishiguchi T, Matsuda J, Ohno R, Nakamura A, Kamei $\mathrm{S}$, et al. Human comparative study of zinc and copper excretion via urine after administration of magnetic resonance imaging contrast agents. Radiat Med. 2005;23:322-6.

55. Yamada M, Asano T, Okamoto K, Hayashi Y, Kanematsu M, Hoshi $\mathrm{H}$, et al. High frequency of calcification in basal ganglia on brain computed tomography images in Japanese older adults. Geriatr Gerontol Int. 2013;13:706-10.

56. Valdés Hernández Mdel C, Maconick LC, Tan EM, Wardlaw JM. Identification of mineral deposits in the brain on radiological images: a systematic review. Eur Radiol. 2012;22:2371-81.

57. Bressler JP, Olivi L, Cheong JH, Kim Y, Maerten A, Bannon $\mathrm{D}$. Metal transporters in intestine and brain: their involvement in metal-associated neurotoxicities. Hum Exp Toxicol. 2007;26:221-9.

58. Kanda T, Matsuda M, Oba $\mathrm{H}$, et al. High $\mathrm{T} 1$ signal intensity in dentate nucleus after multiple injections of linear gadolinium chelates response. Radiology. 2015;276:616-7.

59. Gathings RM, Reddy R, Santa Cruz D, Brodell RT. Gadoliniumassociated plaques: a new, distinctive clinical entity. JAMA Dermatol. 2015;151:316-9.

60. Kartono F, Basile A, Roshdieh B, Schwimer C, Shitabata PK. Findings of osseous sclerotic bodies: a unique sequence of cutaneous bone formation in nephrogenic systemic fibrosis. J Cutan Pathol. 2011;38:286-9.

61. Bhawan J, Swick BL, Koff AB, Stone MS. Sclerotic bodies in nephrogenic systemic fibrosis: a new histopathologic finding. J Cutan Pathol. 2009;36:548-52.

62. Grekin SJ, Holcomb MJ, Modi GM, Huttenbach YT, Poythress EL, Diwan AH. Lollipop lesions in nephrogenic systemic fibrosis mimicking a deep fungal infection. J Cutan Pathol. 2012;39:981-4.

63. Kanal E, Tweedle MF. Residual or retained gadolinium: practical implications for radiologists and our patients. Radiology. 2015;275:630-4.

64. FDA drug safety communication: FDA evaluating the risk of brain deposits with repeated use of gadolinium-based contrast agents for magnetic resonance imaging (MRI). US Food and Drug Administration web site. http://www.fda.gov/Drugs/DrugSafety/ucm455386.htm. Published 27 July 2015. Accessed 28 July 2015.

65. Japan Radiological Society and Japanese Society of Nephrology: guidelines for administering gadolinium based contrast agents to patients with renal dysfunction. Japan Radiological Society web site. http://www.radiology.jp/content/files/743.pdf. Published 25 July 2008. Updated 2 September 2009. Accessed 28 July 2015. 